\title{
The Influence of Perceived Personality Characteristics on Positive Attitude Towards and Suitability of a Celebrity as a Marketing Campaign Endorser
}

\author{
Magdalena Bekk ${ }^{1}$ and Matthias Spörrle ${ }^{1,2, *}$

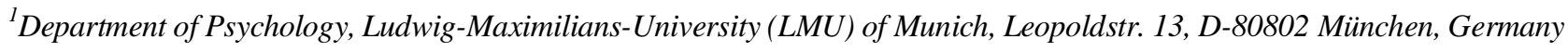 \\ ${ }^{2}$ University of Applied Management (FHAM), Am Bahnhof 2, D-85435 Erding, Germany
}

\begin{abstract}
It is a common strategy to use celebrity endorsers in marketing campaigns. However, scientific literature on the effective use of celebrity endorsers has mainly focused on the credibility and the attractiveness of the celebrity. This study examines another endorser characteristic, which, despite other fields of psychological research confirming its importance, has not received much attention within marketing psychology: the perceived personality. Applying the three culturally stable personality dimensions (i.e., sincerity, excitement, and sophistication) from the established concept of brand personality to the endorser, correlation analyses demonstrated that these personality dimensions of the endorser were related to trustworthiness, a central credibility component, likeability, an important attractiveness component, as well as to positive attitude towards the celebrity and perceived suitability as endorser. Moreover, multiple mediation analyses indicated that the influence of personality dimensions on positive attitude towards the celebrity as well as on perceived suitability of the celebrity as an endorser was to some extent mediated by trustworthiness and likeability. In this context, the personality dimension of excitement emerged as an incrementally valid predictor of positive attitude towards the celebrity as well as perceived suitability as endorser in addition to trustworthiness and likeability. Therefore, the perceived personality of an endorser should be regarded as an important determinant of the central concepts of credibility and attractiveness with the personality dimension of excitement providing incremental value when predicting positive attitudes towards the celebrity and suitability as endorser.
\end{abstract}

Keywords: Celebrity, endorser, endorsement, credibility, trustworthiness, attractiveness, likeability, attitude, suitability as endorser.

\section{INTRODUCTION}

The influence of celebrities as endorsers of a brand on consumer attitudes is of particular interest to both practitioners [e.g., 1-3; cf. 4] and researchers [e.g., 5, 6] alike. In general, endorsers are people who promote products of brands or companies [7]. They can either be typical consumers of the products, experts or celebrities [8]. As demonstrated by Atkin and Block [9] the image of the brand is more positively evaluated and the advert is better remembered when using celebrity endorsers [see also 8]. Therefore, celebrity endorsers (i.e., people who enjoy a high degree of public attention by a large share of the population due to their achievements in areas other than that of the product endorsed) are probably the most frequently used endorser category.

This research examines the determinants of a successful celebrity endorser. We argue that marketing research so far has predominantly put an emphasis on credibility and attractiveness of the celebrity, but has relatively neglected an important social dimension which might explain differences in effectiveness between celebrities of high credibility as well as attractiveness: the perceived personality, i.e., the personality of the celebrity as it is perceived by the

*Address correspondence to this author at the Department of Psychology, Ludwig-Maximilians-University (LMU) of Munich, Leopoldstr. 13, D80802 München, Germany; Tel: ++49-89-2180-5672; Fax: ++49-89-2180-3000; E-mail: spoerrle@psy.uni-muenchen.de consumer. Investigating the potential predictive and incremental value of perceived personality dimensions we propose a model in which established concepts, i.e., source credibility and attractiveness of the endorser, partially mediate the association between the perceived personality characteristics of the celebrity and important determinants of celebrity evaluation while the perceived personality still explains incremental variance in addition to these established concepts. The following sections provide a short overview of the different marketing psychology models and constructs on which the proposed model is based.

Not every person is suitable as an endorser ${ }^{1}$. In particular people who are regarded as being trustworthy $[5,10]$ as well as attractive [11] are seen as suitable spokespersons [for a review see 12-14]. These factors and their impact are described by two relevant models of marketing psychology, namely the source credibility and the source attractiveness model.

The source credibility models states, that the persuasiveness of an endorser depends on how much the consumer feels he can trust the endorser as well as on how much expertise the consumer ascribes to the endorser [cf. 1, 15]. McGinnies and Ward [16] found that trustworthiness compared to expertise emerged as the most important dimension

\footnotetext{
${ }^{1}$ In the following, we will use the word endorser synonymously with celebrity endorsement [cf. 1].
} 
of the source credibility model [cf. 8], which, therefore, represents the source credibility in the following study.

The source attractiveness model on the other hand states, that the persuasiveness of an endorser depends on how attractive the endorser is perceived as well as on how much the consumer likes the endorser [cf. 1, 11]. At this, physical attractiveness is of less importance as celebrities are usually regarded as being attractive [cf. 17]. Moreover, Friedman and Friedman [8] state, that likeableness is the component of the source attractiveness model which is most consistently associated with celebrity endorsers. Therefore, in this study likeability represents the source attractiveness.

However, these two aspects cannot explain why some endorsers are more successful than others, even though consumers regard them as being equally trustworthy and likeable. At this, one has to take into account that, next to credibility and attractiveness components, celebrities additionally embody unique images [cf. 17]. Therefore, the image of the celebrity should be regarded as yet another important variable in the prediction of the evaluation of the endorser by the consumer. In order to assess this image we draw upon the concept of personality which despite its central relevance in other fields of psychology has only rarely been explicitly applied to the examination of endorsers [see for the only peer-reviewed exceptions: 17, 18]. Analogous to the assessment of brand image by means of other-estimated brand personality [cf. 19, 20] it seems advisable to assess the image of a person via his/her perceived personality, i.e., the person's personality as it is perceived by others, in this case by the consumer. At this, Batra and Homer [18] found, in line with the meaning transfer model [21], that the perceived personality of a celebrity endorser can be used to transfer the endorser's image onto the brand and, thus, create a new brand image. Therefore, the perceived personality of an endorser should be regarded as an important component of the endorser's image.

One might argue that assessing an individual's personality by means of ratings of other people is not an adequate approach. However, there are numerous studies from various fields of applied psychological research using otherestimated personality as valid indicators of relevant outcomes. Previous organizational psychological research demonstrated that the perceived organizational personality is related to an organization's attraction and reputation as well as respondents' intention to accept a job offered by this organization [22].

Furthermore, even fundamental research on human personality considers ratings of personality by others a relevant construct. For example, Costa and McCrae [23] developed a stranger-rating version of the revised NEO-Personality Inventory in addition to the self-rating version. Further looking at research on perceived human personality from various fields of psychology, the validity of personality characteristics perceived by others (e.g., supervisors, intimate partners, significant others in general) was demonstrated by associations of these characteristics with relevant criteria (e.g., job performance, partnership length, mental health) [24-28]. At this, observer-ratings of personality accounted for significant variance in criterion measures beyond personality selfratings [24, 27, 28].
Thus, findings across various areas of psychological research (i.e., organizational, personality, social, and clinical psychology) indicate that the personality as it is perceived by others is of utter importance for further evaluations of the appraised person (or object, e.g., organization).

Moreover, within our field of application (i.e., testimonial personality) it seems even better to assess the perceived personality and not the "real" personality by means of the usual self-assessment: It is the perceived personality of a testimonial which is communicated by media and advertisements. For instance, Angelina Jolie might be very shy in real life. However, in her media appearance she is usually quite brave and outspoken. However, as consumers usually get information about the celebrity via the media they will have no idea about the celebrity being shy in reality. Therefore, it would not seem reasonable to assess the personality of a celebrity by means of self-assessments as it is the perceived personality communicated by the media which is used for marketing purposes. Thus, for advertising research it is more adequate to assess the personality of the celebrity as it is perceived by the consumers instead of using a selfassessment of the celebrity's personality.

The perceived personality of an endorser might best be measured by using personality traits of confirmed marketing relevance, i.e., brand personality dimensions (instead of e.g., the Big Five personality model, [cf. 23]). Another reason why the brand personality model rather than models from human personality psychology should be used in order to assess the celebrity's perceived personality, is that customers are usually unable to experience the real personality of the celebrity in natural contexts; through media the line between celebrity and brand has blurred and endorsers themselves are being referred to and regarded as "human brands" [29]. Thus, the image of the celebrity is more similar to marketing-relevant personality dimensions.

Brand personality itself, rather like human personality, consists of different personality factors. In the literature, diverse brand personality factors have been found, depending on the culture and country [e.g., 30-36]. The most established instrument to measure brand personality is Aaker's [30] brand personality scale, which is based on a five-factor solution (i.e., sincerity, excitement, sophistication, competence, ruggedness) partly comparable to the human Big Five personality factors. However, in a study across culturally diverse countries only three of these five factors could be confirmed consistently [31]. Therefore, we limit our analyses to these three personality dimensions, namely sincerity, excitement, and sophistication, as they can be regarded as cross-culturally robust and, thus, as highly relevant in global marketing.

After having introduced these three essential facets of an endorser (i.e., trustworthiness, likeability, and perceived personality dimensions) we now derive our research model (see Fig. 1) linking these aspects with central evaluations of the celebrity (i.e., positive attitude towards the celebrity and perceived suitability as endorser). By doing so, we directly address Choi and Rifon's [17] recent call for future research investigating the associations between a celebrity's image (in this case: perceived personality) and his/her other characteristics (in this case: trustworthiness und likeability) 


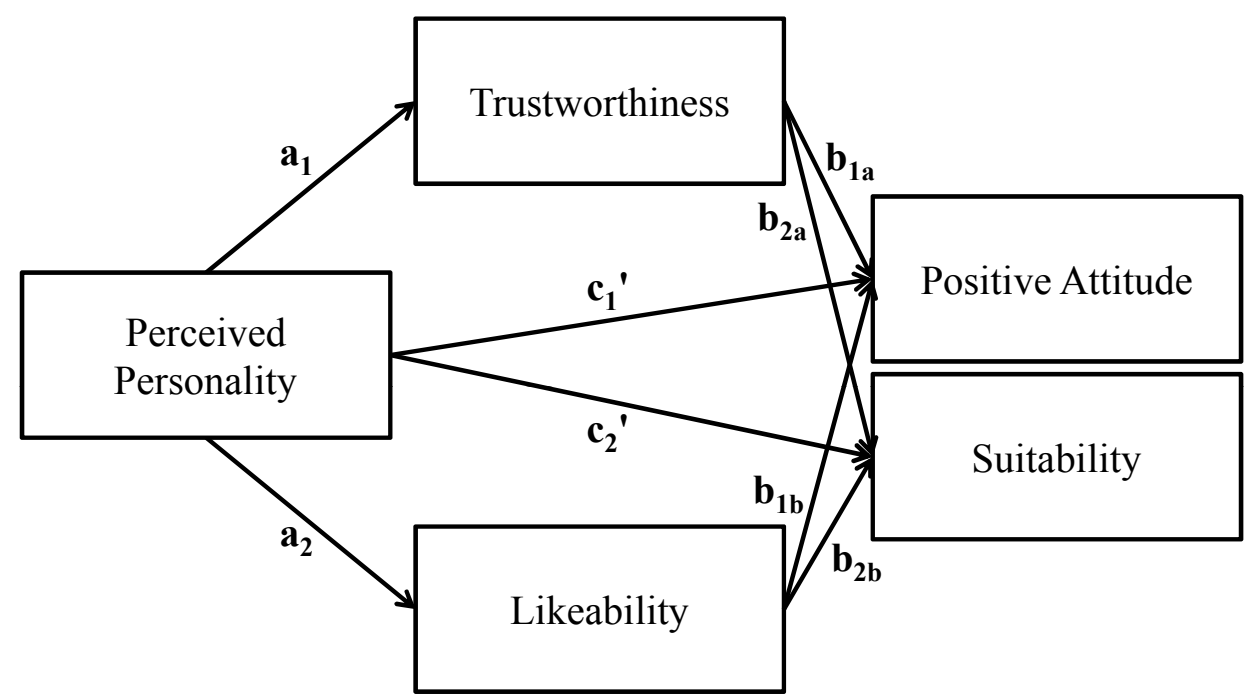

Fig. (1). Proposed model linking perceived endorser personality, trustworthiness and likeability with positive attitude towards and suitability of the celebrity as an endorser.

and the contributions of these constructs on the effectiveness of the celebrity as an endorser. Furthermore, examining the potential impact of perceived personality as an endorser image component within the context of trustworthiness and likeability might explain why celebrities of high trustworthiness as well as high likeability are not always equally suited for specific brands.

Choi and Rifon [17] demonstrated that the perceived personality of the endorser (which they just called image) is significantly related to trustworthiness (i.e., a source credibility model variable) and attractiveness (i.e., a source attractiveness model variable according to [1]). Therefore, we presume positive associations between these endorser characteristics, namely perceived personality, trustworthiness, and likeability. More specifically, it is reasonable to assume a (compared to the other personality dimensions) relatively stronger impact of sincerity when predicting trustworthiness: Based on its meaning sincerity should be particular important for trustworthiness [cf. 30, 31]. Moreover, based on social psychological research underscoring the relevance of honesty as a determinant of positive evaluation [cf. 37] we think that also regarding likeability the construct of sincerity should be relatively more important than the other two personality characteristics.

How are these characteristics associated with positive attitudes towards the endorser? Since Silvera and Austad [38] could show that variables from the source attractiveness model were related to attitude towards the endorser it seems justifiable to assume an association between likeability and positive attitudes towards the endorser. Even though there is no direct empirical evidence corroborating the correlation of trustworthiness and personality with positive attitudes towards the endorser there are findings supporting this assumption: Deshpandé and Stayman [39] showed that increased trustworthiness attributed to a spokesperson led to more positive attitudes towards the brand promoted by this spokesperson. Given this far-reaching impact of endorser trustworthiness on positive attitudes towards the promoted brand it seems almost compelling to assume the proximate association between trustworthiness of and positive attitudes towards the endorser. Finally, as perceived personality, just as likeability and trustworthiness, can be regarded as a characteristic of the endorser we claim that it, too, is related to positive attitude towards the celebrity (especially when considering the evaluative nature of some personality characteristics, cf. sincerity). We, therefore, presume that there will be positive associations between celebrity characteristics (i.e., likeability, trustworthiness, and perceived personality) on the one hand and positive attitude of the consumer towards the celebrity on the other hand. Regarding the causal direction of these assumed associations previous advertising and persuasion research indicates that source characteristics such as credibility led to an increased positive attitude and not vice versa [cf. 39-41]. We, therefore, hypothesize that endorser characteristics (i.e., likeability, trustworthiness, and perceived personality) influence positive attitude towards the endorser (see $\mathrm{b}_{1 \mathrm{a}}, \mathrm{b}_{1 \mathrm{~b}}$ and $\mathrm{c}_{1}$ ' paths in Fig. 1).

We now turn to the hypothesized sequence model of the predictors of positive attitudes towards the endorser. In an organizational context Strauss, Barrick, and Connerley [25] were able to show that the influence of personality characteristics (i.e., more trait-like variables) on outcome variables was partially mediated by liking (i.e., a more state-like variable due to its relatively stronger situational dependence, [cf. 42]). With regard to the causal direction Chen, Gully, Whiteman, and Kilcullen [43] could show that state-like characteristics mediate the influence of trait-like characteristics on outcome variables. Transferred to our research we, therefore, assume a mediation model of perceived personality on positive attitude towards the celebrity mediated by trustworthiness and likeability (see $a_{1}, a_{2}, b_{1 a}$ and $b_{1 b}$ paths in Fig. 1). As described before, the mediation of sincerity as an important determinant of trustworthiness and likeability should be relatively stronger than that of the other personality characteristics, whereas for excitement as a not very value-laden variable the indirect effect should be relatively weaker. Looking at organizational psychology research once again, results indicate that personality directly (and not only indirectly) predicts attitudes [e.g., 44, 45]. Thus, perceived endorser personality is assumed to explain incremental vari- 
ance in addition to source credibility and attractiveness on positive attitude towards the celebrity (see $\mathrm{c}_{1}$ ' path in Fig. 1), thus, further substantiating the predictive relevance of personality characteristics. This might be especially true for the perceived personality dimension of excitement which seems to be a more independent and less value-laden variable in comparison to sincerity and sophistication, which entail positive valence. It is easy to imagine a person perceived as being exciting and energetic without necessarily being trustworthy or likeable at the same time. Thus, it is plausible to presume that excitement will be the perceived personality dimension least influenced by either of the two mediators, trustworthiness and likeability.

Paralleling these delineations concerning positive attitudes towards the endorser, an additional dependent variable is included in this research: It is not only important to predict consumers' general positive attitudes towards an endorser (unrelated to marketing campaign applications), but also to predict whether or not a celebrity is perceived as being specifically suitable as a marketing campaign endorser. Even though this variable (i.e., suitability as an endorser) is very likely to be significantly correlated with attitudes towards the endorser it can be assumed to represent the broader concept considering not only attitudes but also additional marketingrelevant characteristics (e.g., cultural fit). Again we propose a model in which more state-like characteristics, i.e., trustworthiness and likeability, mediate the influence of more trait perceived personality characteristics on suitability of the celebrity as endorser (see $a_{1}, a_{2}, b_{2}$ and $c_{2}$ ' paths in Fig. 1). Still perceived trait personality is assumed to incrementally predict suitability of the celebrity as an endorser, too (see $\mathrm{c}_{2}$ ' path in Fig. 1).

Summarizing all considerations described so far, the assumed associations can be integrated within a single research hypothesis (see Fig. 1):

Hypothesis: The positive impact of perceived personality dimensions (i.e., sincerity, excitement, and sophistication) when predicting (1) positive attitude towards the celebrity as well as (2) suitability of the celebrity as an endorser are partially and simultaneously mediated by (a) trustworthiness (i.e., a source credibility variable) and (b) likeability (i.e., a source attractiveness variable).

\section{METHOD}

Participants. Overall, 220 German students (50\% male, $50 \%$ female) participated in this paper-pencil survey. Their average age was 24.31 years (ranging from 19 to $39, S D=$ 3.29). In terms of statistical power analysis this sample can be regarded as having a sufficient sample size for the intended regression analyses [cf. 46].

Procedure. Each participant received a photo of one out of the ten (five female, five male) famous celebrities used as stimuli in this study (i.e., George Clooney, Sean Connery, Jonny Depp, Jodie Foster, Angelina Jolie, Keira Knightley, Keanu Reeves, Julia Roberts, Bruce Willis, Kate Winslet). Celebrities were selected on the basis of their familiarity, as provided by ranking lists, i.e., Forbes celebrity 100 or star currency lists, and should, furthermore, represent somewhat different personalities. The latter was assessed by using personality attributes perceived by film consumers which were provided in some of the Forbes rankings as well as by comparing the roles the celebrities had recently played. Additionally, participants were asked to indicate the familiarity of the celebrity. All of the celebrities were well known and analysis of variance did not result in any difference as to the familiarity of the celebrities in our sample. Participants were then asked to rate the celebrity's perceived personality characteristics, trustworthiness and likeability, as well as to indicate their positive attitude towards this person and the suitability of this celebrity as an endorser. Participants were always able to see the photo of the celebrity while providing their answers. No connections between the celebrity and any specific brands were made.

Perceived Celebrity Personality. As perceived celebrity personality measure we used single-item indicators of the three culturally stable brand personality dimensions, i.e., sincerity, excitement, and sophistication. We took three adjectives, i.e., sincere [aufrichtig], energetic [energiegeladen] and stylish [stilvoll], from the studies of Aaker, Benet-Martínez and Garolera [31] as high factor loadings of these items indicate their high dimensional representativeness. Despite potential reliability limitations, single-item measures are commonly used in applied settings such as marketing [e.g., 47-49] or organizational psychology [e.g., 50-52]. Wanous, Reichers, and Hudy [53] could show in a meta-analysis that single-item and multiple-item measures of job satisfaction correlated strongly, indicating that singleitem measures of psychological constructs are acceptable in terms of reliability and validity. Recently, Woods and Hampson [54] developed a Big Five personality measure with one item per dimension showing acceptable reliability and strong correlations with multiple-item personality measures. We, therefore, believe that using single items is an economic and acceptable way to examine the hypothesized model for the first time.

Trustworthiness. We used a four-item scale to assess participants' trust in the celebrity (sample item: "I would trust this person") on five-point-scales ranging from 0 (= strongly disagree) to 4 (= strongly agree). The scale was found to be highly reliable according to Peterson [55], Cronbach's alpha $=.92$ (see Appendix for all items of this and subsequent scales).

Likeability. We used a four-item scale to assess participants' likeability of the celebrity (sample item: "I like this person") on five-point-scales ranging from 0 (= strongly disagree) to 4 (= strongly agree). The scale was found to be highly reliable, Cronbach's alpha $=.88$.

Positive attitude towards celebrity. We used six bipolar items drawn from the measures of Mattenklott [56], e.g., negative/positive, Silvera and Austad [38], e.g., unpleasant/pleasant, and of Swaminathan, Page, and GürhanCanli [57], e.g., bad/good, to assess positive attitude towards the celebrity. This scale was highly reliable, Cronbach's alpha $=.85$.

Suitability of celebrity as endorser. We used a four-item scale to assess the suitability of the celebrity as an endorser (sample item: "Would you recommend this person as an endorser to a company") on five-point-scales ranging from 0 
Table 1. Descriptive Statistics, Intercorrelations, and Reliabilities of the Assessed Variables

\begin{tabular}{|c|c|c|c|c|c|c|c|c|c|c|c|c|c|c|}
\hline & $M$ & $S D$ & $S K$ & $\boldsymbol{K} \boldsymbol{U}$ & (1) & (2) & (3) & (4) & (5) & (6) & (7) & (8) & (9) & (10) \\
\hline (1) Age & 24.31 & 3.29 & 1.72 & 3.70 & - & -.16 & .00 & .04 & .04 & .15 & .08 & .02 & -.06 & -.05 \\
\hline (2) Participant sex & - & - & - & - & -.13 & - & .00 & .08 & -.06 & .02 & .02 & .10 & .07 & .01 \\
\hline (3) Celebrity sex & - & - & - & - & -.02 & .00 & - & -.05 & -.03 & .02 & -.14 & -.12 & -.13 & -.14 \\
\hline (4) Sincerity & 2.21 & 1.02 & -0.22 & -0.29 & .06 & .05 & -.03 & - & .10 & .49 & .67 & .61 & .52 & .31 \\
\hline (5) Excitement & 2.56 & 1.06 & -0.53 & -0.13 & .03 & -.06 & -.02 & .04 & - & .24 & .16 & .31 & .34 & .30 \\
\hline (6) Sophistication & 2.76 & 1.13 & -0.65 & -0.43 & .17 & .01 & .04 & .44 & .19 & - & .47 & .61 & .51 & .36 \\
\hline (7) Trustworthiness & 1.97 & 0.89 & -0.13 & -0.30 & .08 & -.01 & -.16 & .64 & .15 & .47 & $(.92)$ & .69 & .60 & .40 \\
\hline (8) Likeability & 2.59 & 0.90 & -0.68 & 0.34 & .00 & .06 & -.10 & .58 & .28 & .56 & .70 & (.88) & .72 & .49 \\
\hline (9) Positive attitude & 2.51 & 0.91 & -0.48 & -0.03 & -.08 & .05 & -.11 & .51 & .28 & .49 & .59 & .73 & (.85) & .58 \\
\hline $\begin{array}{l}\text { (10) Suitability as } \\
\text { endorser }\end{array}$ & 2.52 & 0.97 & -0.54 & -0.05 & -.05 & -.02 & -.14 & .27 & .26 & .31 & .38 & .46 & .54 & $(.87)$ \\
\hline
\end{tabular}

Notes:

$M=$ Mean, $S D=$ Standard Deviation; $S K=$ Skewness, $K U=$ Kurtosis; $N=220$. Since most skewness and kurtosis values are within the range of -1.00 and +1.00 suggested by Muthén and Kaplan [60] parametric analyses seem justified. However, as there was some deviation from normality for age, we additionally computed Spearman's nonparametric rank correlations which overall were very similar to Pearson's correlation, thus indicating that the parametric indicators of association are not severely influenced by these deviations. For Pearson correlation (above main diagonal): $|r| \geq .14, p<.05$ (two-tailed), $|r| \geq .18, p<.01$ (two-tailed). For Spearman rank correlation (below main diagonal): $|r| \geq .14, p<.05$ (two-tailed), $|r| \geq .19, p<.01$ (two-tailed). Within main diagonal: Reliabilities (Cronbach's alpha).

(= not at all) to 4 (= very much). The scale was found to be highly reliable, Cronbach's alpha $=.87$.

\section{RESULTS}

With regard to the sex of the celebrity we detected small to medium sized but significant effects indicating sex differences within this specific stimulus person set: Concerning the source credibility variable, trustworthiness of the celebrity, we found a significant correlation $(r=-.14)$, indicating that male celebrities were seen as being more trustworthy. When looking at the source attractiveness variable, likeability, we found a significant correlation $(r=-.12)$, indicating that male celebrities were regarded as being more likeable. Finally, male celebrities were associated with an increase in attitude towards the celebrity $(r=-.13)$ and were also regarded as being more suitable as an endorser $(r=-.14)$ than female celebrities.

We assumed a positive connection between the perceived personality of the celebrity and the variables from the source credibility and source attractiveness model. In line with this we found significant positive correlations between all perceived personality dimensions and trustworthiness as well as likeability, which according to Cohen [58] were medium to large $(r \mathrm{~s}>30)$, apart from the small correlation between excitement and trustworthiness $(r=.16)$ (see Table 1).

When looking at the relations between the perceived personality dimensions and positive attitude towards the celebrity as well as suitability of the celebrity as endorser we found significant medium to large correlations $(r s \geq .30)$ in the expected directions, thus, providing first support for our model.

There were significant medium to large correlations $(r s \geq$ .40) between the variables form the source credibility and source attractiveness model on the one hand and both positive attitude towards the celebrity and suitability as endorser on the other hand. ${ }^{2}$

Subsequently, we performed two multiple blockwise entry regression analyses in order to further investigate the impact of celebrity perceived personality, source credibility, and source attractiveness when predicting positive attitude towards the celebrity as well as suitability as an endorser. In order to predict positive attitude towards the celebrity we first entered the covariates (i.e., age, sex of respondent, sex of celebrity), then the perceived personality dimensions and finally trustworthiness and likeability in the regression analysis (see Table 2). There were neither age nor gender

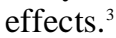

When entering the perceived personality dimensions into the analysis sex of the celebrity as well as age significantly predicted positive attitude. More importantly, all three perceived personality dimensions simultaneously predicted positive attitude towards the celebrity significantly, and, together, accounted for $41 \%$ of the variance.

\footnotetext{
${ }^{2}$ Based on these correlations one might argue, that the variables examined merely represent one single factor of general positive evaluation of the endorser. However, factor analytic procedures revealed that these constructs (i.e., likeability, trustworthiness, positive attitude towards endorser, suitability as endorser, and perceived personality characteristics) are correlated but separable: Results of the Minimum-AveragePartial (MAP) test [59] indicated the existence of three factors: (1) sophistication, likeability, and positive attitude towards endorser, (2) trustworthiness and sincerity, and (3) suitability as endorser. Excitement loaded on all three factors, but relatively low. Therefore, the assumption of one single factor is not supported by the data.

${ }^{3}$ We tested for any sex interaction effects [cf. 61, 62] which did not reach significance for either of the two dependent variables, attitude towards celebrity and suitability as endorser.
} 
Table 2. Regression Model Predicting Positive Attitude Towards Celebrity

\begin{tabular}{|c|c|c|c|c|c|c|c|c|}
\hline & $\beta$ & $S E_{r o b}$ & $\boldsymbol{\beta}$ & $S E_{r o b}$ & $\Delta \boldsymbol{R}_{a d j}^{2}$ & $\beta$ & $S E_{r o b}$ & $\Delta \boldsymbol{R}_{a d j}^{2}$ \\
\hline Age & -.05 & .07 & $-.13 * *$ & .05 & & $-.11 *$ & .05 & \\
\hline Participant sex & .06 & .07 & .03 & .05 & & .01 & .04 & \\
\hline Celebrity sex & -.13 & .07 & $-.11^{*}$ & .05 & & -.04 & .05 & \\
\hline Sincerity & & & $.34 * * *$ & .06 & & .06 & .07 & \\
\hline Excitement & & & $.23 * * *$ & .05 & & $.14^{* *}$ & .05 & \\
\hline \multirow[t]{2}{*}{ Sophistication } & & & $.31 * * *$ & .06 & & .11 & .06 & \\
\hline & & & & & $.41 * * *$ & & & \\
\hline Trustworthiness & & & & & & $.18^{*}$ & .08 & \\
\hline \multirow[t]{2}{*}{ Likeability } & & & & & & $.45 * * *$ & .12 & \\
\hline & & & & & & & & $.14 * * *$ \\
\hline
\end{tabular}

Notes:

$R^{2}$. 56. The final regression model is significant, $F(8,211)=36.16, p<.001$. Analyses of the tolerance values $(>.36)$ and the condition indices $(<3.50)$ do not indicate any collinearity problems of the predictors. Analyses of the residuals do indicate heteroscedasticity in our data (Breusch-Pagan/Cook-Weisberg-test and White-test significant, $p<.001$, respectively). Therefore, we estimated robust standard errors $\left(S E_{r o b}\right)$ to adjust for the heteroscedastic distribution.

$* p \leq .05$ (two-tailed); ** $p \leq .01$ (two-tailed); *** $p \leq .001$ (two-tailed).

In the third step, when entering trustworthiness and likeability, both variables had a significant predictive impact on positive attitude and accounted for additional 14\% of the variance. Even though both of the source relevant variables had a significant influence on positive attitude, excitement still remained significant. Therefore, excitement seemed to be the, comparatively, most important perceived personality dimension to directly predict positive attitude towards the celebrity. However, considering that the predictive power of all perceived personality dimensions was reduced when the source relevant variables were entered, these results implicate a model in which the influence of celebrity perceived personality on positive attitude is mediated by trustworthiness and likeability.

To test this model in line with our hypothesis, we performed three multiple mediation analyses (one for each perceived personality dimension as predictor) based on bootstrap sampling (5.000 resamples) according to the approach of Preacher and Hayes [63] in order to simultaneously investigate the influence of all three perceived personality dimensions on positive attitude towards the celebrity while using trustworthiness and likeability as mediators and controlling for covariates (see Fig. 2). As covariates we again used age, sex of participant, sex of celebrity and, additionally, within each mediation analysis the two other perceived personality dimensions, respectively, which were not investigated as predictor (this was done in order to control for the intercorrelations between sincerity and sophistication as well as between excitement and sophistication).

In line with the regression analysis, results indicated a reduced but still significant direct positive association between the perceived personality dimension excitement and positive attitude towards celebrity which cannot be explained either by the mediators or the covariates. Therefore, excitement seemed to be the, comparatively, most important per- ceived personality dimension of the three to directly predict positive attitude towards the celebrity. Looking at the two mediators, we found that the associations between all three perceived personality dimensions on the one hand and positive attitude towards the celebrity on the other hand were mediated (for excitement only partially) by likeability (point estimate of indirect effect for sincerity: .182, $p<.05$, bias corrected and accelerated $95 \%$ confidence interval $[B C a$ $95 \% C I] .064$ to .275 ; point estimate for excitement: $.085, p$ $<.05, \mathrm{BCa} 95 \% \mathrm{CI} .021$ to .158; point estimate for sophistication: $.170, p<.05, B C a 95 \% C I .073$ to .271). When looking at the second mediator, trustworthiness, only predictive impacts of sincerity and sophistication were mediated by trustworthiness (point estimate for sincerity: .101, $p<.05$, $B C a 95 \% C I .022$ to .218 ; point estimate for sophistication: $.032, p<.05, B C a 95 \%$ CI .006 to .089). Trustworthiness did not mediate the connection between excitement and positive attitude ( $\mathrm{BCa} 95 \% \mathrm{CI}-.005$ to .037). To sum up, the proposed mediation model was supported for all three perceived personality dimensions concerning the mediation through likeability but only for sincerity and sophistication concerning trustworthiness as mediator.

An explorative comparison of the indirect effects of both mediators by means of pairwise contrasts indicated that the specific indirect effect through likeability was significantly larger than the specific indirect effect through trustworthiness for excitement (point estimate .076, BCa 95\% CI .008 to .145) and for sophistication (point estimate $.138, B C a$ $95 \% C I .008$ to .245$)$. There was no significant difference of the indirect effects for sincerity ( $B C a 95 \% C I-.144$ to .226 ). Thus, the mediation by likeability was significantly stronger than the mediation by trustworthiness for excitement and sophistication.

Paralleling our previous analyses in a second regression analysis, we tested the influence of the same predictors only 


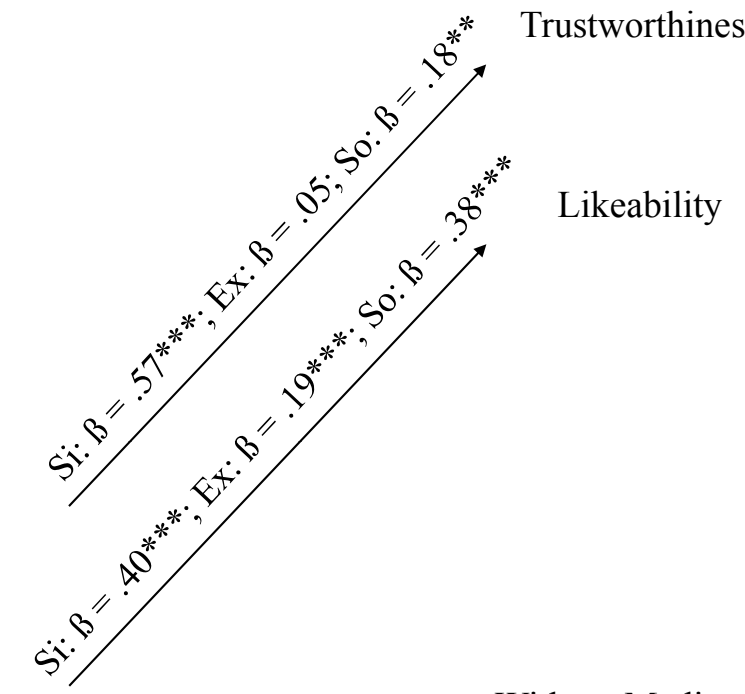

Without Mediators:
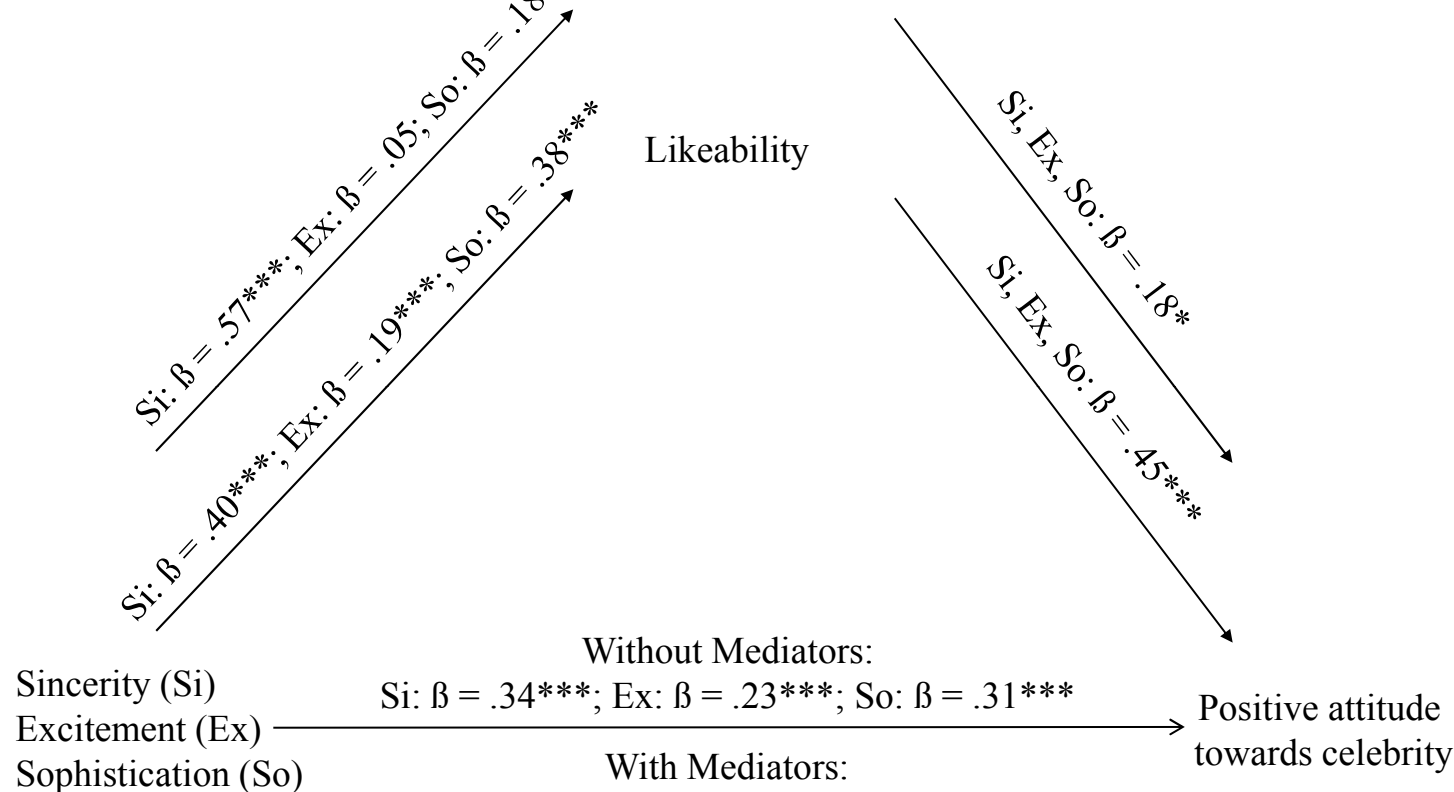

$$
\text { Si: } \beta=.06 \text {; Ex: } \beta=.14 * * ; \text { So: } \beta=.11
$$

Fig. (2). Influence of perceived celebrity personality dimensions on positive attitude towards the celebrity (partially) mediated through trustworthiness and likeability.

Notes: $* p \leq .05$ (two-tailed); $* * p \leq .01$ (two-tailed); $* * * p \leq .001$ (two-tailed).

this time predicting suitability of the celebrity as an endorser. We entered the covariates (age, sex of participant, sex of celebrity) first into the analysis and found a significant effect of the celebrity's sex, indicating that participants found male celebrities as being more suitable as endorser (see Table 3).

This effect remained significant when entering the perceived personality dimensions in the second step. Most important, again all three perceived personality dimensions significantly predicted suitability of the celebrity as endorser, and accounted for additional $20 \%$ of the variance. Therefore, perceived personality of the celebrity cannot only be regarded as being an important predictor of positive attitude towards the celebrity but also of the suitability of this person as an endorser.

Finally, we again added the source credibility and attractiveness variables in the last step. This time only the source attractiveness component, likeability, was a significant predictor of suitability as endorser. This step accounted for additional $6 \%$ of the variance. Again, excitement out of the three perceived personality dimensions stayed significant in the last step, thus, indicating that this dimension might be the, comparatively, most important perceived personality dimension in the prediction of suitability as endorser, too. However, considering that the predictive power of all perceived personality dimensions was reduced when the source relevant variables were entered, these results, again, implicate a model in which the influence of celebrity perceived personality on suitability of the celebrity as endorser is mediated by trustworthiness and likeability.

However, as $\Delta R^{2}$ differed by $100 \%$ compared to the squared multiple correlation of the previous analysis we tested the significance of the difference by computing the confidence intervals for the two squared multiple correla- tions $\left[R^{2}\right]$ with the program by Steiger and Fouladi [64], first. Results of the exact confidence intervals indicate that the squared multiple correlation of the three perceived personality dimensions and positive attitude towards the celebrity, $R^{2}$ $=.41,95 \%$ exact confidence interval $[95 \% C I] .301$ to .502 , is significant different from zero as well as significantly larger than the squared multiple correlation of the three perceived personality dimensions and suitability of the celebrity as endorser, $R^{2}=.20,95 \%$ exact confidence interval [95\% CI] .104 to .291 , which is significantly different from zero.

To test this second model, linking perceived personality, likeability, trustworthiness and suitability of endorser, we, again, performed three multiple mediation analyses (one for each perceived personality dimension) based on bootstrap sampling (5.000 resamples) according to the approach of Preacher and Hayes [63] in order to simultaneously investigate the influence of all three perceived personality dimensions on suitability of the celebrity as endorser while using trustworthiness and likeability as simultaneous mediators and controlling for covariates (see Fig. 3). We used the same covariates as in the previous multiple mediation analysis.

In line with the regression analysis, results indicated reduced but still significant direct positive associations with suitability as endorser for the perceived personality dimension excitement which cannot be explained either by the mediators or the covariates. Looking at the two mediators, we found that the associations between all three perceived personality dimensions on the one hand and suitability as endorser on the other hand were mediated (for excitement only partially) by likeability (point estimate of indirect effect for sincerity: $.116, p<.05$, bias corrected and accelerated $95 \%$ confidence interval $[B C a 95 \% C I] .016$ to .220 ; point 
Table 3. Regression Model Predicting Suitability as Endorser

\begin{tabular}{|c|c|c|c|c|c|c|c|c|}
\hline Age & -.05 & .07 & -.11 & .06 & & -.09 & .06 & \\
\hline Celebrity sex & $-.14^{*}$ & .07 & $-.13 *$ & .06 & & -.08 & .06 & \\
\hline \multirow[t]{2}{*}{ Sophistication } & & & $.24 * * *$ & .07 & & .11 & .08 & \\
\hline & & & & & $.20 * * *$ & & & \\
\hline Trustworthiness & & & & & & .14 & .09 & \\
\hline
\end{tabular}

Notes:

$R_{a d j}^{2}=.27$. The final regression model is significant, $F(8,211)=11.04, p<.001$. Analyses of the tolerance values $(>.36)$ and the condition indices $(<3.50)$ do not indicate any collinearity problems of the predictors. Analyses of the residuals do not indicate heteroscedasticity in our data (Breusch-Pagan/Cook-Weisberg-test and White-test nonsignificant, respectively).

$* p \leq .05$ (two-tailed); ** $p \leq .01$ (two-tailed); $* * * p \leq .001$ (two-tailed).

estimate for excitement: .054, $p<.05, \mathrm{BCa} 95 \% \mathrm{CI} .008$ to .117 ; point estimate for sophistication: $.109, p<.05, B C a$ $95 \%$ CI .020 to .208). When looking at the second mediator, trustworthiness, no significant indirect effects between the three perceived personality dimensions and suitability as endorser were found (for sincerity: $B C a 95 \% C I-.041$ to .207 ; for excitement: $B C a 95 \% C I-.004$ to .043 ; for sophistication: $B C a 95 \% C I-.012$ to .077). To sum up, the proposed mediation model was supported for all perceived personality dimensions concerning the mediation through likeability but not for trustworthiness as mediator.

An explorative comparison of the indirect effects of both mediators by means of pairwise contrasts indicated that there was no significant difference of the indirect effects for any of the three perceived personality dimensions (sincerity: $B C a$ 95\% CI -.169 to .232 ; excitement: $B C a 95 \% C I-.009$ to .109 ; sophistication: $B C a 95 \% C I-.031$ to .199). Such apparent paradoxes, that there is no significant difference between the indirect effects of two mediators even though one mediator is significantly different from zero, whereas the other is not, can occur when one of the specific indirect effects involved in the contrast is not sufficiently far from zero [63, p. 886].

\section{DISCUSSION}

This research sheds some light onto the associations between the so far empirically relatively neglected concept of perceived celebrity personality within the context of other characteristics of the celebrity, i.e., source credibility and source attractiveness, as well as their respective contributions to consumers' positive attitudes towards the celebrity and the estimated suitability of the celebrity as an endorser.

We were able to show, that perceived personality was related to trustworthiness, a central component of source credibility, as well as to likeability, an important aspect of source attractiveness. Moreover, perceived personality explained $41 \%$ of the variance when predicting positive attitude towards the endorser. At this, one of the perceived personality dimensions, namely excitement, remained significant when adding trustworthiness and likeability, which reached significance as well. A similar pattern occurred when predicting suitability of the celebrity as an endorser. The three perceived personality dimensions explained $20 \%$ of the variance. Again, excitement remained significant when adding trustworthiness and likeability into the analysis. However, this time out of the components of the two source characteristic models only likeability but not trustworthiness proved to be a significant predictor of suitability. Therefore, we can conclude that in addition to established source characteristics, i.e., source credibility and attractiveness, perceived personality is an important construct influencing consumers' positive attitudes towards an endorser. Moreover, the perceived personality dimension of excitement has incremental validity in addition to the established concepts when predicting perceived suitability as an endorser.

Even though the three perceived personality dimensions had a significant impact on both outcome variables, i.e. positive attitude towards celebrity and suitability of endorser, we noticed a large difference as to the explained variance of perceived personality on these outcome variables. Perceived personality had a significantly larger influence on positive attitude towards the celebrity than on suitability of endorser. This might be due to the fact, that perceived personality might be more important for intuitive social evaluations, but less pivotal for expert-like, quasi-objective judgments.

We assumed a mediation model in which the association between the more trait-like concept of perceived personality on the one hand and positive attitude towards the celebrity as well as suitability of the celebrity as endorser on the other hand would be mediated by more situation-dependent state- 


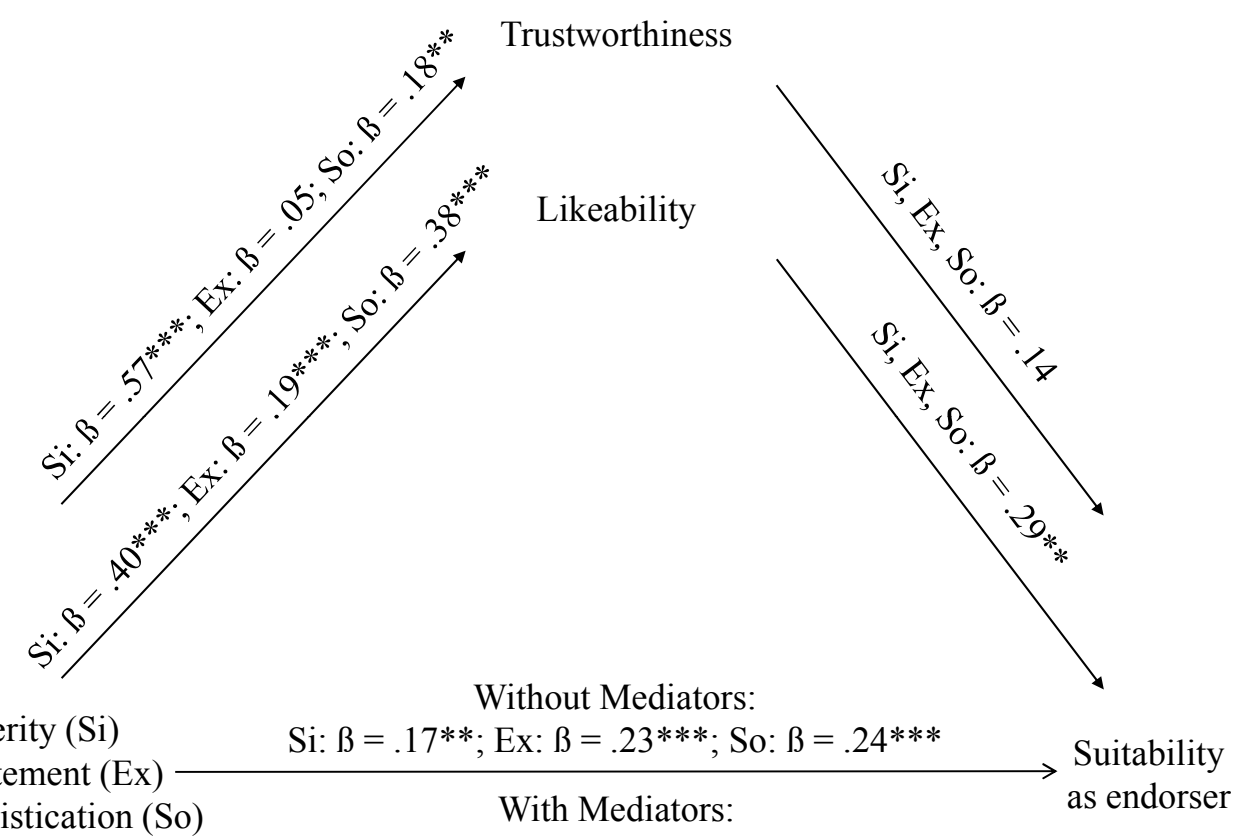

$\begin{array}{lcl}\text { Sincerity ( } \mathrm{Si}) & \text { Si: } \beta=.17^{* *} \text {; Ex: } \beta=.23^{* * *} \text {; So: } \beta=.24 * * * \\ \text { Excitement }(\mathrm{Ex}) \longrightarrow \text { With Mediators: } & \text { Suitability } \\ \text { Sophistication (So) } & \text { as endorser }\end{array}$

Si: $\beta=-.02 ; \mathrm{Ex}: \beta=.17^{* *}$; So: $\beta=.11$

Fig. (3). Influence of perceived celebrity personality dimensions on suitability as endorser (partially) mediated through trustworthiness and likeability.

Notes: $* p \leq .05$ (two-tailed); $* * p \leq .01$ (two-tailed); *** $p \leq .001$ (two-tailed).

like concepts, i.e., source credibility and attractiveness components, i.e., trustworthiness and likeability. Our findings confirmed this model. The association between the perceived trait personality dimensions and positive attitude towards the celebrity was fully mediated by the state-like variables, i.e., trustworthiness and likeability, for the perceived personality dimensions sincerity and sophistication and partially mediated for the perceived personality dimension excitement. At this, likeability proved itself to be the stronger mediator for the perceived personality dimensions excitement and sophistication. Additionally, likeability, was the only significant mediator of the association between the perceived personality dimensions and suitability of the celebrity as an endorser. These findings indicate that likeability might be a more important determinant of celebrity evaluations than trustworthiness. Again, there was only a partial mediation for the perceived personality dimension excitement, indicating its incremental validity. With this model we were able to describe the concepts preceding the source credibility and source attractiveness model variables which previous research had neglected. Our results indicate that trait characteristics, like perceived personality, influence participants' perception of trustworthiness and likeability of a celebrity and provide incremental power when predicting celebrity evaluations.

We can conclude that source credibility, i.e., trustworthiness, and source attractiveness, i.e., likeability, are relevant predictors of source effectiveness as could be shown in previous research [e.g., 8, 11, 16]. Of these two variables likeability has proved itself to be the more important predictor on both effectiveness measures, i.e., positive attitude and suitability. Furthermore, trustworthiness only showed a significant influence on positive attitude towards the celebrity but not on suitability as endorser. Looking at the definition of the source credibility model this is surprising. According to the source credibility model which implies trustworthiness and expertise [1], trustworthiness might be expected to be important for expert-like, quasi-objective judgments, which was not the case. However, our results are in line with a previous study [65] comparing the effects of trustworthiness and likeability, which could show that source likeability was more strongly correlated to evaluation of product attributes and the intention to perform a specific behavior than source trustworthiness. Thus, it might be possible that likeability is the more important variable of the two source variables. However, as likeability and trustworthiness were strongly correlated in our study as well as in a study by Friedman, Santeramo and Traina [66] both variables should be empirically considered.

Even more important, we were able to demonstrate for the first time that the perceived personality dimension of excitement provided incremental predictive validity, thus, denoting the existence of an empirically accessible concept explaining existing suitability differences between equally trustworthy and likable endorsers. Therefore, perceived personality should be regarded as an important underlying predictor of endorser effectiveness within the context of source credibility and source attractiveness. With regard to the indirect effect of perceived personality on source effectiveness via trustworthiness and likeability sincerity should be regarded as the most important personality dimension, having the greatest influence of all predictors on trustworthiness and likeability. When looking at excitement, however, we can state that it was the weakest determinant of either trustworthiness or likeability in our study when predicting positive attitude as well as suitability. Therefore, this dimension 
seems to be the most important personality dimension when looking at the direct influence of perceived personality on consumer evaluation. This result is in line with a study by Phau and Lau [67] who could show, that consumers initial personality preference significantly influences how they perceive the personality of a preferred brand of theirs. This direct effect was strongest for the brand personality dimension excitement. Freling and Forbes [68] found out that people who had information about one of the brand personality dimensions for a particular brand showed significantly more positive attitudes towards that brand. At this, manipulation in sincerity showed the most influence on positive attitudes (corresponding to the mediators in our study). A manipulation of the dimension sophistication resulted in the highest purchase intentions. Thus, the influence of the distinct brand personality dimensions differs among previous studies. Our study might, therefore, be able to shed some more light on these diverse results by including mediating variables.

In this study we followed the call for research by Choi and Rifon [17] to investigate the associations between an image of a celebrity (in our study: perceived personality) and other aspects of the celebrity, i.e., source credibility and attractiveness, as well as their contributions to the effectiveness of the celebrity as an endorser. However, we did not measure source effectiveness by assessing consumer behavior or attitude towards the advertisement or brand as most of the previous research has done [e.g., 39, 69], but rather followed the approach of Silvera and Austad [38] measuring positive attitude towards the celebrity. Moreover, we did not only want to assess the consumer's general evaluation of the celebrity but rather wanted the consumer to give a statement as to whether the celebrity was suitable as an endorser or not.

A first limitation of our study is that we did not examine the influence of the variables investigated on attitude towards a brand or product. Even though, Silvera and Austad [38] found that the attitude towards the endorser predicted attitude towards the product, thus, supporting the relevance of our model, future research should examine the associations between endorser related source effectiveness variables, i.e., positive attitude towards celebrity and suitability as endorser, and established brand-related variables, e.g., attitude towards the brand [39, 69], as well as consumer behavior, e.g., purchase intentions [69], in order to test whether endorser-related effectiveness variables are valid predictors of advertising effectiveness.

In this context it might also be interesting for future research to examine the effect of a fit between the endorser and the specific endorsed product or brand as stated by the match-up-hypothesis [e.g., 70, 71]. It is plausible that a good fit will increase consumers' evaluations of the celebrity, in particular the celebrity's suitability as endorser.

Furthermore, we did only use single-item measures to assess the three marketing relevant cross-culturally stable personality dimensions. These items had all been used by Aaker, Bente-Martínez, and Garolera [31] and can, thus, be regarded as valid representatives of their respective dimension. However, single-items will always be less reliable than multiple-item scales. It is, therefore, all the more surprising that they were such strong predictors given the fact that low reliability can only reduce but never increase associations
[72]. Nevertheless, future research should investigate perceived endorser personality using multiple-item personality measures in order to precisely estimate its impact.

Another limitation of our study might be the use of a student sample. However, even though students are not a representative sample, they have to be regarded as an important group of consumers. Moreover, research indicates, that adolescents are, compared to elder people, more influenced by spokesperson as they are role models to them [e.g., 73, 74], thus making them an attractive target group to celebrity advertisement campaigns. The significant regression weights of age on positive attitude towards the celebrity support this statement, that younger people hold more favorable attitudes of the celebrities. However, this does not make them representative as to all consumer groups. In order to be able to further generalize our results, future research should investigate the presented model using larger and representative consumer samples.

Three implications to advertisers and researchers can be derived from our research. First, we simultaneously examined the source attractiveness and credibility variables. Integrating these separate branches of research allowed us to give recommendations as to the relative importance of these two marketing-relevant constructs. Our results indicated that likeability was a better predictor than trustworthiness for both positive attitude as well as suitability of the endorser. Moreover, likeability was a stronger mediator of excitement and sophistication on positive attitude towards the celebrity than trustworthiness. Thus, not only do likeability and trustworthiness differ in their predictive value but also in their potential to mediate the connection between perceived personality dimensions and positive attitude. Therefore, our findings indicate that within marketing campaigns practitioners should place specific emphasis on likeability compared to trustworthiness, as a likable celebrity will lead to comparatively more positive attitude towards this person. As regards future studies, more researchers should examine attractiveness and expertise variables simultaneously in their studies in order to replicate, support and generalize our findings that likeability is the stronger variable.

Second, our findings were in line with the hypothesized model conceptualizing perceived personality as an antecedent of relevant source-related variables, i.e., likeability and trustworthiness, which proved to be important predictors of consumer-related outcome variables in previous research. Thus, our model implies a causal succession in which perceived personality influences likeability and credibility perceptions. We, therefore, recommend to practitioners to select celebrities scoring high on those perceived personality traits that have profound impact on the pivotal characteristics of likeability and trustworthiness, i.e. sincerity and sophistication.

Third, not only were we able to show that perceived personality is an antecedent of the source attractiveness and source credibility variables, but, moreover, explains incremental variance of the consumer-related dependent variables, i.e., positive attitude and suitability as endorser. Thus, a specific aspect of perceived personality, i.e., excitement, can be regarded as another important predictor of consumers' 
attitudes. We, therefore, recommend to both practitioners and researchers to consider the perceived personality dimension excitement as an additional independent predictor of positive attitude as well as suitability.

Concluding, we can state that the celebrity's perceived personality clearly influences consumers' evaluation of a celebrity as a marketing campaign endorser and should, thus, be seen as a relevant concept within advertising research. This corresponds to marketing research looking at the perceived personality of non-human entities, which indicates that perceived brand personality is e.g., an essential determinant of brand image in general [18] and intention to recommend [75] as well as of evaluations of companies' internet representations in particular [76]. Moreover, a strong brand personality leads to more favorable brand associations and higher purchase intentions [68]. Further extending these findings, our research indicates that perceived personality should not be neglected in advertising research using human entities as well.

\section{APPENDIX}

Items used to assess trustworthiness, likeability, positive attitude towards the celebrity and suitability of the celebrity as an endorser.

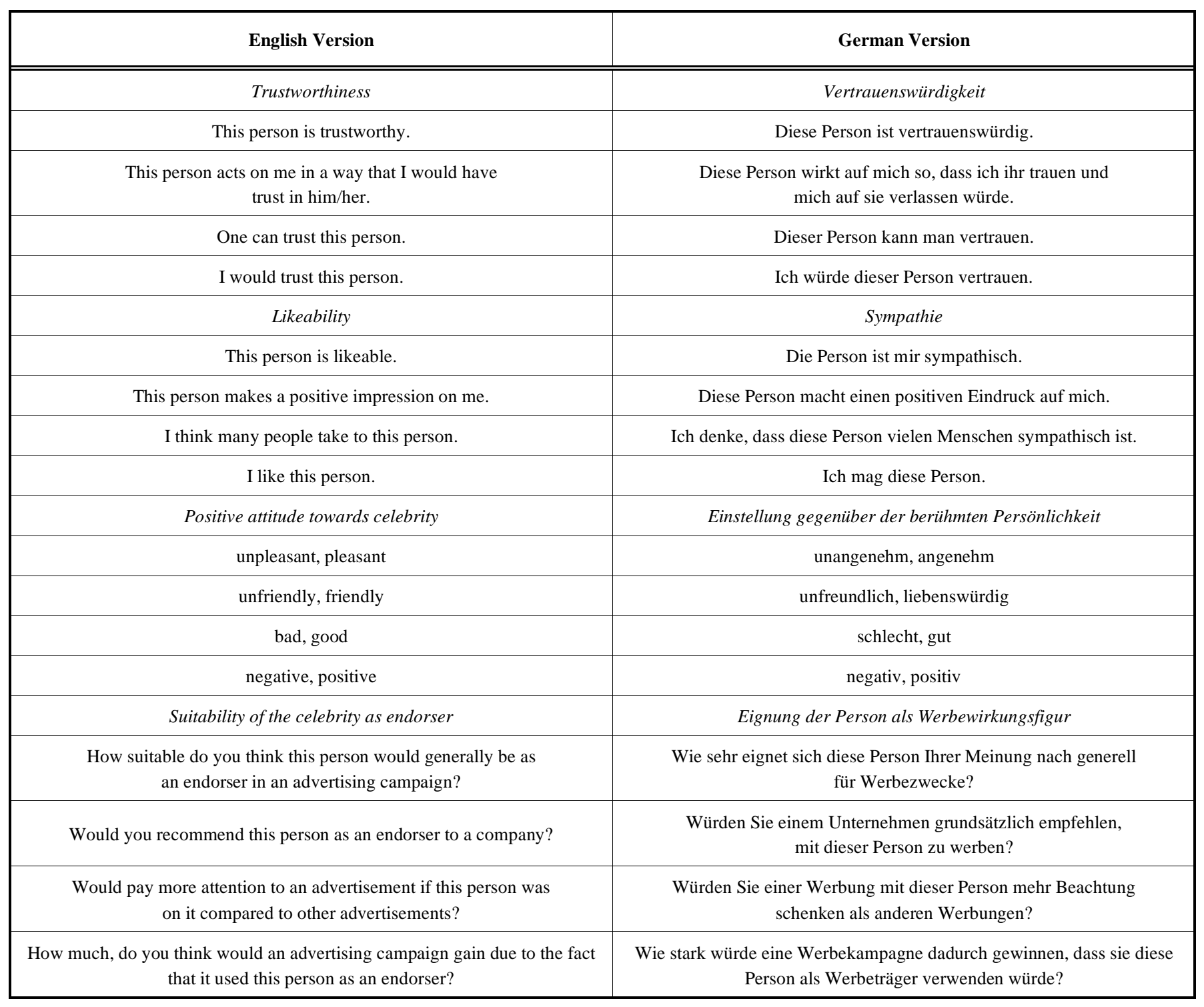

\section{REFERENCES}

[1] Erdogan BZ. Celebrity endorsement: a literature review. J Market Manag 1999; 15: 291-314

[2] Erdogan BZ, Drollinger T. Endorsement practice: How agencies select spokespeople. J Advert Res 2008; 48: 573-82.
[3] Thompson S. Celebrating celebrities in advertising. The Times, Business, Retailing 2008.

[4] Misra S, Beatty SE. Celebrity spokesperson and brand congruence. J Bus Res 1990; 21: 159-73.

[5] Amos C, Holmes G, Strutton D. Exploring the relationship between celebrity endorser effects and advertising effectiveness - 
A quantitative synthesis of effect size. Int J Advert 2008; 27: 209234.

[6] Till BD, Stanley SM, Priluck R. Classical conditioning and celebrity endorsers: An examination of belongingness and resistance to extinction. Psychol Market 2008; 25: 179-96.

[7] Felser G. Werbe- und Konsumentenpsychologie [Advertising- and consumer psychology]. Berlin: Spektrum Akademischer Verlag 2007.

[8] Friedman HH, Friedman L. Endorser effectiveness by product type. J Advert Res 1979; 19: 63-71.

[9] Atkin C, Block M. Effectiveness of celebrity endorsers. J Advert Res 1983; 23: 57-61.

[10] Pornpitakpan C. The effect of celebrity endorsers' perceived credibility on product purchase intention: the case of Singaporeans. J Int Consum Market 2003; 16: 55-74.

[11] Kahle LR, Homer PM. Physical attractiveness of the celebrity endorser: a social adaptation perspective. J Consum Res 1985; 11: 954-61.

[12] Becker F, Rosenstiel Lv, Spörrle M. Persuasion durch Glaubwürdigkeit [Persuasion through credibility]. In: Moser K, Ed. Wirtschaftspsychologie [Economic Psychology], Heidelberg: Spinger 2007; pp. 69-84.

[13] Kahle KE, Kahle LR. Sports celebrities' image: a critical evaluation of the utility of Q scores. In: Kahle LR, Kim, CH, Eds. Creating images and the psychology of marketing communication, mahwah, NJ: Lawrence Erlbaum 2006; pp. 191-200.

[14] Neumann P. Markt- und Werbepsychologie [Market- and advertising psychology], Gräfelfing: Fachverlag Wirtschaftspsychologie 2003.

[15] Pornpitakpan C. The persuasiveness of source credibility: A critical review of five decades' evidence. J Appl Soc Psychol 2004; 34 : 243-81.

[16] McGinnies E, Ward CD. Better liked than right: Trustworthiness and expertise as factors in credibility. Pers Soc Psychol Bull 1980; 6: 467-72.

[17] Choi SM, Rifon NJ. Who is the celebrity in advertising? Understanding dimensions of celebrity images. J Pop Cult 2007; 40: 30424.

[18] Batra R, Homer PM. The situational impact of brand image beliefs. J Consum Psychol 2004; 14: 318-30.

[19] Biel A. How brand image drives brand equity. J Advert Res 1992; 32: 6-12.

[20] Moser K. Die Psychologie der Marke [The psychology of the brand]. Wirtschaftspsychologie aktuell 2001; 8: 10-7.

[21] McCracken G. Who is the celebrity endorser? Cultural foundations of the endorsement process. J Consum Res 1989; 16: 310-21.

[22] Slaughter JE, Zickar MJ, Highhouse S, Mohr DC. Personality trait inferences about organizations: development of a measure and assessment of construct validity. J Appl Psychol 2004; 89: 85103.

[23] Costa PT, McCrae RR. Manual for the Revised NEO Personality Inventory (NEO-PI-R) and the NEO Five-Factor Inventory (NEOFFI). Odessa, FL: Psychological Assessment Resources 1992.

[24] Miller JD, Pilkonis PA, Clifton A. Self- and other-reports of traits from the Five-Factor Model: Relations to personality disorder. J Pers Disord 2005; 19: 400-19.

[25] Strauss JP, Barrick MR, Connerley ML. An investigation of personality similarity effects (relational and perceived) on peer and supervisor ratings and the role of familiarity and liking. J Occup Organ Psychol 2001; 74: 637-57.

[26] Little AC, Burt DM, Perrett DI. What is good is beautiful: Face preference reflects desired personality. Pers Indiv Differ 2006; 41: 1107-18.

[27] Mount MK, Barrick MR, Strauss JK. Validity of observer ratings of the big five personality factors. J Appl Psychol 1994; 79: 27280 .

[28] Leung S-K, Bond MH. Interpersonal communication and personality: Self and other perspectives. Asian J Soc Psychol 2001; 4: 6986.

[29] Thomson M. Human brands: Investigating antecedents to consumers' strong attachments to celebrities. J Market 2006; 70: 102-19.

[30] Aaker JL. Dimensions of brand personality. J Market Res 1997; 34: 347-56.

[31] Aaker JL, Benet-Martinez V, Garolera J. Consumption symbols as carriers of culture: A study of Japanese and Spanish brand personality constructs. J Pers Soc Psychol 2001; 81: 492-508.
Bosnjak M, Bochmann V, Hufschmidt T. Dimensions of brand personality attributions: a person-centric approach in the German cultural context. Soc Behav Pers 2007; 35: 303-16.

[33] Geuens M, Weijters B, De Wulf K. A new measure of brand personality. Int J Res Market 2009; 26: 97-107.

[34] Hieronimus F. Persönlichkeitsorientiertes Markenmanagement [personality oriented brand management]. Frankfurt am Main: Peter Lang, Europäischer Verlag der Wissenschaften 2003.

[35] Mäder R. Messung und Steuerung von Markenpersönlichkeit: Entwicklung eines Messinstruments und Anwendung in der Werbung mit prominenten Testimonials [Measurment and management of brand personality. Development of a brand personality measure and its application in advertising using celebrity endorsers]. Wiesbaden: Deutscher Universitäts Verlag 2005.

[36] Sung Y, Tinkham SF. Brand personality structures in the United States and Korea: Common and culture-specific factors. J Consum Psychol 2005; 15: 334-50.

[37] Pandey J, Singh AK. Attribution and evaluation of manipulative social behavior. J Soc Psychol 1986; 126: 735-44.

[38] Silvera DH, Austad B. Factors predicting the effectiveness of celebrity endorsement advertisements. Eur J Market 2004; 38: 1509-26.

[39] Deshpandé R, Stayman DM. A tale of two cities: Distinctiveness theory and advertising effectiveness. J Market Res 1994; 31: 5764.

[40] Tormala LZ, Briñol P, Petty RE. When credibility attacks: The reverse impact of source credibility on persuasion. J Exp Soc Psychol 2006; 42: 684-91

[41] Yoon K, Kim CH, Kim M-S. A cross-cultural comparison of the effects of source credibility on attitudes and behavioral intentions. Mass Commun Soc 1998; 1: 153-73.

[42] Till BD, Shimp TA. Endorsers in advertising: The case of negative celebrity information. J Advert 1998; 27: 67-82.

[43] Chen G, Gully SM, Whiteman J-A, Kilcullen RN. Examination of relationships among trait-like individual differences, state-like individual differences, and learning performance. J Appl Psychol 2000; 85: 835-47.

[44] Bernerth JB, Armenakis AA, Feild HS, Giles WF, Walker HJ. Is personality associated with perceptions of LMX? An empirical study. Leader Organ Dev J 2007; 28: 613-31.

[45] Smith MA, Canger JM. Effects of supervisor "Big Five" personality on subordinate attitudes. J Bus Psychol 2004; 18: 465-81.

[46] Green SB. How many subjects does it take to do a regression analysis? Multivar Behav Res 1991; 26: 499-510.

[47] Bergkvist L, Rossiter JR. The predictive validity of multiple-item versus single-item measures of the same constructs. J Market Res 2007; 44: 175-84.

[48] Rossiter JR. The C-OAR-SE procedure for scale development in marketing. Int J Res Market 2002; 19: 305-35.

[49] van Doorn J, Verhoef PC. Critical incidents and the impact of satisfaction on customer share. J Market 2008; 72: 123-42.

[50] Nagy MS. Using a single-item approach to measure facet job satisfaction. J Occup Organ Psychol 2002; 75: 77-86.

[51] Scarpello V, Campbell JP. Job satisfaction: are all parts there? Pers Psychol 1983; 36: 577-600.

[52] Shamir B, Kark R. A single-item graphic scale for the measurement of organizational identification. J Occup Organ Psychol 2004; 77: 115-23.

[53] Wanous JP, Reichers AE, Hudy MJ. Overall job-satisfaction: how good are single-item measures? J Appl Psychol 1997; 82: 247-52.

[54] Woods SA, Hampson SE. Measuring the Big Five with single items using a bipolar response scale. Eur J Personality 2005; 19: 373-90.

[55] Peterson RA. A meta-analysis of Cronbach's coefficient alpha. J Consum Res 1994; 21: 381-91.

[56] Mattenklott A. Emotionale Werbung [Emotional advertising]. In: Moser K, Ed. Wirtschaftspsychologie [Economic Psychology], Heidelberg: Spinger 2007; pp. 86-106.

[57] Swaminathan V, Page KL, Gürhan-Canli Z. "My" brand or "our" brand: The effects of brand relationship dimensions and self-construal on brand evaluations. J Consum Res 2007; 34: 24859.

[58] Cohen J. Statistical power analysis for the behavioral sciences Hillsdale, NJ: Lawrence Erlbaum Associates 1988.

[59] O'Connor BP. SPSS and SAS programs for determining the number of components using parallel analysis and Velicer's MAP test. Behav Res Methods, Inst Comp 2000; 32: 396-402. 
[60] Muthen B, Kaplan D. A comparison of some methodologies for the factor analysis of non-normal Likert variables. Br J Math Stat Psychol 1985; 38: 171-89.

[61] Agthe M, Spörrle M. On the context sensitivity of the sexual attribution bias: A replication and extension to situations of failure. Open Psychol J 2009; 2: 19-24.

[62] Agthe M, Spörrle M, Försterling F. Success attributions and more: Multidimensional extensions of the sexual attribution bias to failure attributions, social emotions, and the desire for social interaction. Per Soc Psychol B 2008; 34: 1627-38.

[63] Preacher KJ, Hayes AF. Asymptotic and resampling strategies for assessing and comparing indirect effects in multiple mediator models. Behav Res Methods 2008; 40: 879-91.

[64] Steiger JH, Fouladi RT. R2: A Computer program for interval estimation. Power calculation, and hypothesis testing for the squared multiple correlation. Behav Res Methods, Inst Comp 1992; 4: $581-82$

[65] O'Hara BS, Netemeyer RG, Burton S. An examination of the relative effects of source expertise, trustworthiness, and likability. Soc Behav Pers 1991; 19: 305-14.

[66] Friedman HH, Santeramo MJ, Traina A. Correlates of trustworthiness for celebrities. J Acad Market Sci 1978; 6: 291-99.

[67] Phau I, Lau KC. Brand personality and consumer self-expression. Single or dual carriageway? Brand Manage 2001; 8: 428-44.

[68] Freling TH, Forbes LK. An empirical analysis of the brand personality effect. J Prod Brand Manage 2005; 14: 404-13.
[69] Goldsmith RE, Lafferty BA, Newell SJ. The impact of corporate credibility and celebrity credibility on consumer reaction to advertisements and brands. J Advert 2000; 29: 43-54.

[70] Kamins MA. An investigation into the "match-up" hypothesis in celebrity advertising: When beauty may be only skin deep. J Advert 1990; 19: 4-13.

[71] Till BD, Busler M. The match-up hypothesis: Physical attractiveness, expertise, and the role of fit on brand attitude, purchase intent and brand beliefs. J Advert 2000; 29: 1-13.

[72] Cohen J, Cohen P, West SG, Aiken LS. Applied multiple regression/correlation analysis for the behavioral sciences. Mahwah, New Jersey: Lawrence Erlbaum Associates 2003.

[73] Bush AJ, Martin CA, Bush VD. Sports celebrity influence on the behavioral intentions of generation Y. J Advert Res 2004; 44: 10818 .

[74] Giles DC, Maltby J. The role of media figures in adolescent development: Relations between autonomy, attachment, and interest in celebrities. Pers Indiv Differ 2004; 36: 813-22.

[75] Ekinci Y, Hosany S. Destination personality: An application of brand personality to tourism destinations. J Trav Res 2006; 45: 127-39.

[76] Park S, Choi D, Kim J. Visualizing e-brand personality: Exploratory studies on visual attributes and e-brand personalities in Korea. Int J Hum Comput Interact 2005; 19: 7-34. 